Corrigendum

\title{
Corrigendum to "An Insight into Methods and Practices in Hip Arthroplasty in Patients with Rheumatoid Arthritis"
}

\author{
Mohammad Saeed Mosleh-shirazi, ${ }^{1}$ Mazin Ibrahim, ${ }^{1}$ Philip Pastides, ${ }^{2}$ Wasim Khan, \\ Habib Rahman, ${ }^{1}$ and Leila Jahangiri ${ }^{3}$ \\ ${ }^{1}$ Heart of England NHS Foundation Trust, Birmingham Heartlands Hospital, Bordesley Green East, Birmingham B9 5SS, UK \\ ${ }^{2}$ Royal Free London NHS Foundation Trust, London NW3 2QG, UK \\ ${ }^{3}$ Ludwig Institute for Cancer Research, University of Oxford, Oxford, UK
}

Correspondence should be addressed to Philip Pastides; ppastides@hotmail.com

Received 26 October 2016; Accepted 3 November 2016

Copyright (C) 2016 Mohammad Saeed Mosleh-shirazi et al. This is an open access article distributed under the Creative Commons Attribution License, which permits unrestricted use, distribution, and reproduction in any medium, provided the original work is properly cited.

In the article titled "An Insight into Methods and Practices in Hip Arthroplasty in Patients with Rheumatoid Arthritis" [1], Dr. Leila Jahangiri was missing from the authors' list. Dr. Jahangiri contributed to the writing and revision of the article. The corrected authors' list is shown above.

\section{References}

[1] M. S. Mosleh-Shirazi, M. Ibrahim, P. Pastides, W. Khan, and H. Rahman, "An insight into methods and practices in hip arthroplasty in patients with rheumatoid arthritis," International Journal of Rheumatology, vol. 2015, Article ID 140143, 6 pages, 2015. 


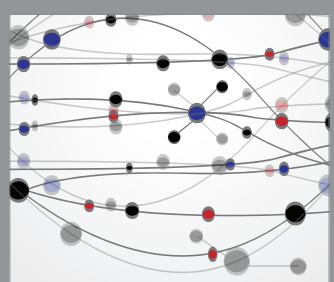

The Scientific World Journal
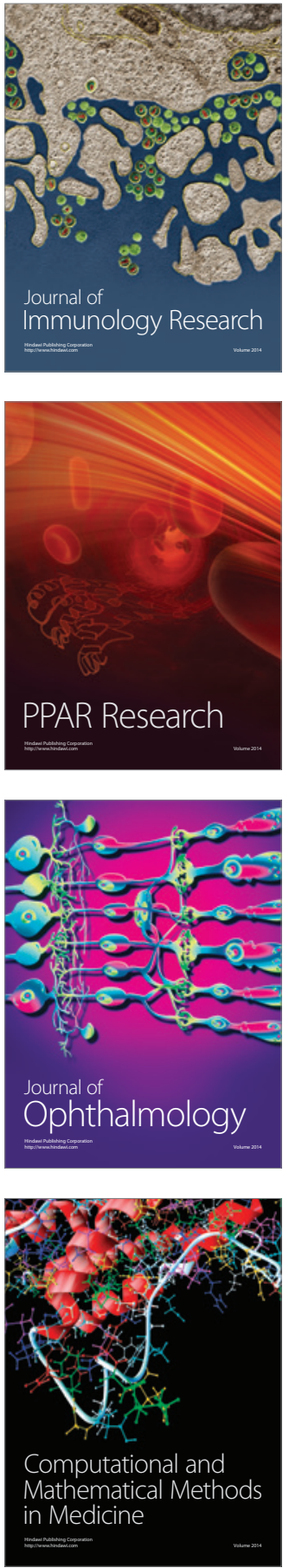

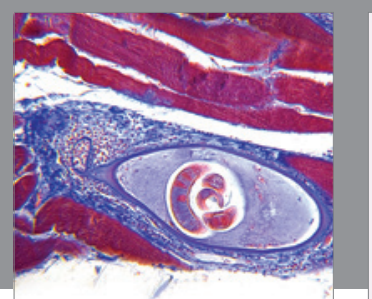

Gastroenterology Research and Practice

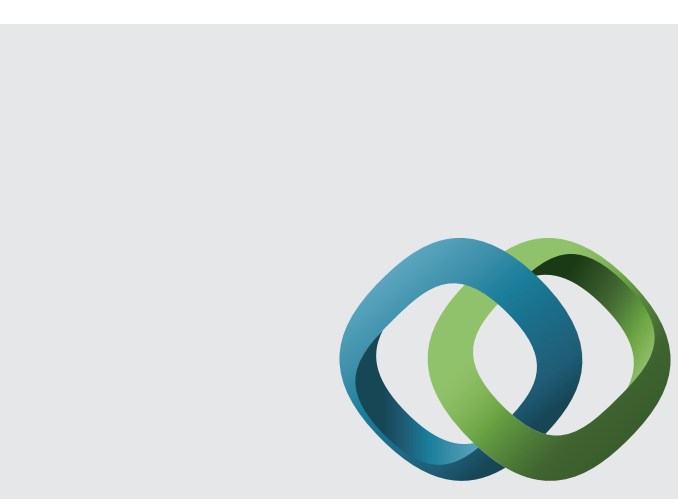

\section{Hindawi}

Submit your manuscripts at

http://www.hindawi.com
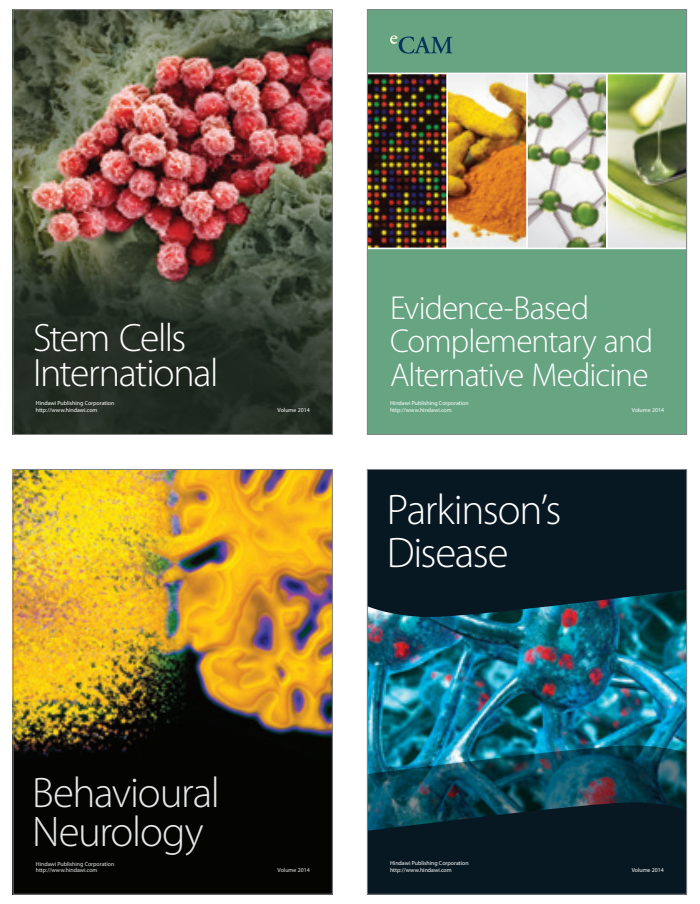
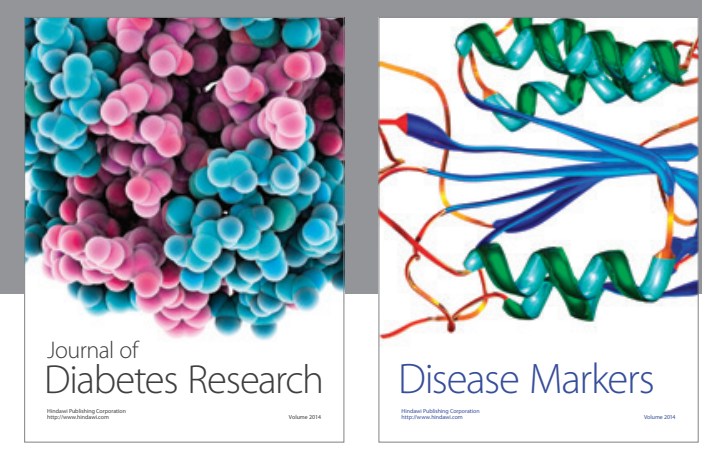

Disease Markers
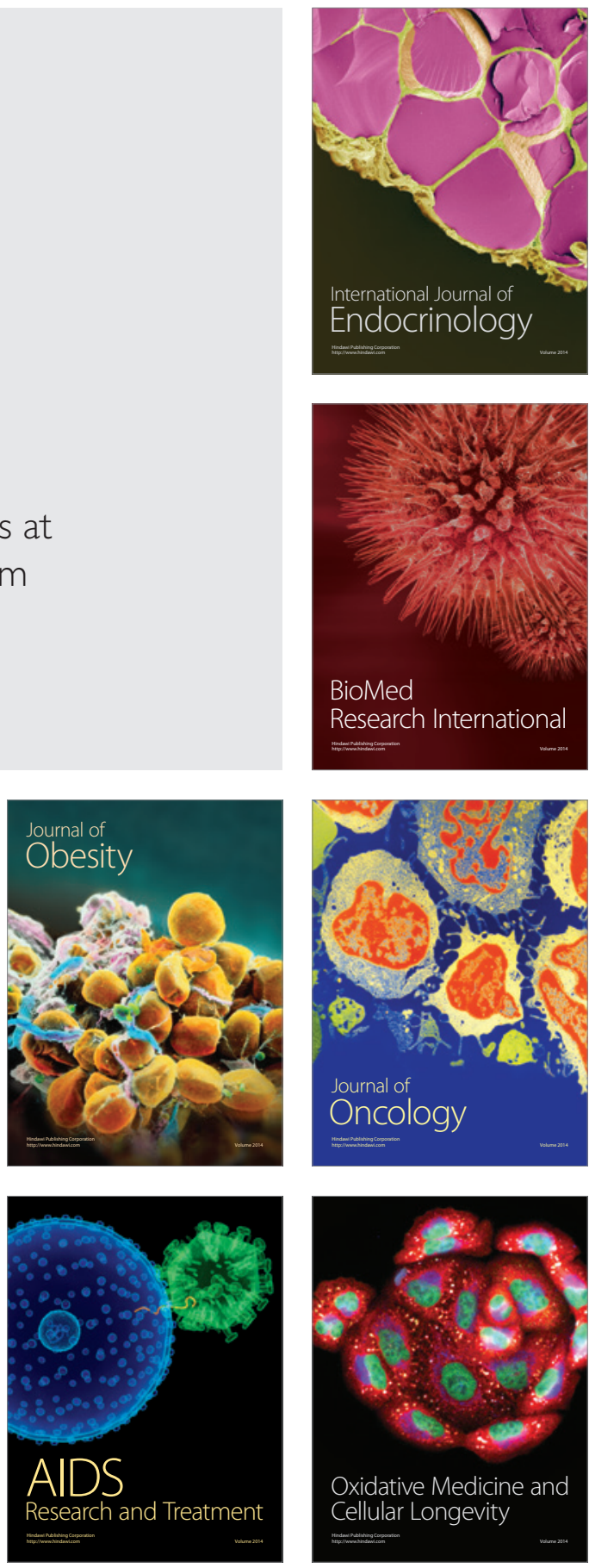